Trakya Eğitim Dergisi

Cilt 9, Sayı 2

Mayıs 2019, 199-210

Geliș Tarihi: 27.05 .2018

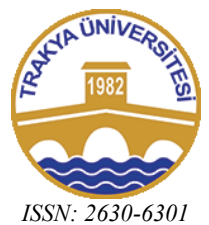

ISSN: 2630-6301
Trakya Journal of Education

Volume 9, Issue 2

May 2019, 199-210

\title{
Blog Kullanımının Yabancı Dil Olarak Türkçe Öğrenenlerin Okumaya Yönelik Tutumları Üzerindeki Etkisi
}

\author{
Effectiveness of Blog Use on Attitudes towards Reading by Learners of Turkish as a \\ Foreign Language
}

\section{Murat Sami TÜRKER ${ }^{1}$}

\begin{abstract}
Öz: İçinde yaşadığımız dünyanın giderek dijitalleştiği çağımızda, teknolojide yaşanan gelişmelerin eğitim alanında da yansımalarını görmek kaçınılmazdır. Geleneksel yabancı dil öğretim yöntemlerinin modern eğitim anlayışının gerektirdiği iletişim ve teknoloji ihtiyaçlarını karşılamada yetersiz oluşu, teknoloji destekli yabancı dil öğretim malzemeleri ve öğrenme ortamları ile yeni yaklaşım ve yöntemlerin geliştirilmesini zorunlu kılmıştır. Yaşam boyu öğrenme becerilerinin tartış1ldığ 1 eğitim dünyasında sınıf içinde ve sınıf dışında teknoloji ile desteklenmiş öğrenme ortamları oluşturulmasının sayısız yararlar sağlayacağı düşünülmektedir. Teknolojiye olan düşkünlükleriyle bilinen "z kuşağı” öğrencilerin ihtiyaç duydukları etkileşimli dil ögrenme ortamları, sahip oldukları teknolojik araçlar da göz önünde bulundurulduğunda, "ağ günlükleri" olarak da bilinen bloglar olarak karşımıza çıkmaktadır. Bu çalışma, blog şeklinde teknolojik tabanlı bir sınıf dışı ögrenme ortamının yabancı dil olarak Türkçe öğrenenlerin okumaya karşı tutumları üzerindeki etkisini araştırmaktadır.

Çalışma, B2 düzeyinde Türkçe öğrenen 52 yabanc1 uyruklu öğrencinin katılımıyla yürütülmüştür. Sekiz haftalık planlanan bu araştırma kapsamında araştırmacı tarafından özgün bir blog sitesi tasarlanmış, hazırlanan içerik bir ders dışı etkinlik olarak uygulanmıştır. Öğrencilerin okumaya yönelik tutumlarının saptanması amacıyla, çalışma öncesi ve çalışma sonrasında okuma tutum ölçeği uygulanarak elde edilen veriler nicel yöntemlerle analiz edilmiştir. Çalışmanın sonuçları, öğrencilerin okumaya yönelik tutumlarında uygulama sonunda pozitif yönlü anlamlı bir değişim olduğunu göstermiştir.
\end{abstract}

Anahtar sözcükler: Yabancı dil olarak Türkçe öğretimi, Web 2.0 araçları, blog, okumaya karşı tutum.

\begin{abstract}
In our age, in which the world is digitalized day by day, it is inevitable that we see the reflections of technological developments in the field of education. Since traditional foreign language teaching methods are inadequate to meet the communication and technology needs of modern education system, technology supported foreign language teaching materials and learning environments and new approaches and methods have to be developed. It is thought that the creation of learning environments supported by technology within the classroom and outside the classroom is considered to provide numerous benefits in the education world where lifelong learning skills are discussed. The interactive language learning environments needed by the "Generation Z" students, known for their indulgence in technology, are emerging as blogs, also known as "web diaries", when the technological opportunities they have are taken into consideration. This study investigates the effectiveness of a blog-based out-ofclass learning environment on the attitudes of Turkish as a foreign language students towards reading.

The study was conducted with the participation of 52 foreign students learning Turkish in B2 level. Within the scope of this eight-week planned study, a blog page was designed by the researcher and the prepared content was applied as an extracurricular activity. In order to determine the students' attitudes towards reading, the data obtained by applying reading attitude scale before and after the study were analyzed by quantitative methods. The results showed that there was a significant positive change in the students' attitudes towards reading by the end of the study.
\end{abstract}

Keywords: Teaching Turkish as a foreign language, Web 2.0 tools, blog, attitudes towards reading.

\section{EXTENDED ABSTRACT}

\section{Introduction}

Reading is not just decoding written symbols in a text as many people think, but rather a complex process involving the interaction between the reader and the text. In this process, readers are active participants who try to make sense of what they read in interaction with the text (Silberstein, 1994, s. 6). Since it is the basic means of accessing information and learning at all levels of instruction takes place largely through reading, it is important to have technical knowledge and skills needed for an effective reading experience and positive attitudes towards reading (Sainsbury, 2004, s. 49) since students' attitudes towards reading have a significant effect on their reading performance (Lipson ve Wixson, 2013, s. 52).

\footnotetext{
1 Öğr. Gör. Dr., Anadolu Üniversitesi, Açıköğretim Fakültesi, Öğrenme Teknolojileri Ar-Ge Birimi, muratsturker@gmail.com, ORCID: 0000-0002-2037-8508
} 
In language learning environments, there has been a shift from traditional approaches to modern approaches recently. The common belief that teachers are responsible for transferring knowledge to students is no longer true. Today, learners are in the center of teaching and learning process. They are active individuals who reach the information, solve problems by using the information they have obtained and produce new information. Teachers' responsibility, on the other hand, should be to strive to maximize the capacity of students, such as a team coach (Özden, 2008, ss. 67, 78-79).

There is no doubt that the first thing to do in a learner centered approach is to determine student needs and interests. Considering the skills and tendency of today's students to use technology, it is impossible to design a learning environment without including the latest technological developments. Technology is the most effective way of extending learning beyond classroom and personalizing learning. With the emergence of the internet and the developments in mobile technologies, web 2.0 tools, especially blogs have become essential learning tools in foreign language learning environments. The interactive language learning environments needed by the "Generation Z" students, known for their indulgence in technology, are emerging as blogs, also known as "web diaries", when the technological opportunities they have are taken into consideration. This study investigates the effectiveness of blog use on the attitudes of students towards reading.

\section{Method}

This study was conducted with the participation of 52 students learning Turkish as a foreign language in B2 level. The study was designed as an out-of-class activity without requiring any resource books such as dictionaries, textbooks or grammar books. Also the students were encouraged to use their mobile devices throughout the study. For these reasons, B2 level students, who are independent users of the language, were decided to be the participants of the study.

Within the scope of this study, a blog page was originally designed by the researcher and the reading content was created through newspaper articles and Turkish stories in order to provide authentic language samples. The implementation process of the study lasted for eight weeks and a reading attitude scale was used before and after the implementation process to investigate the effectiveness of blog use on learners' attitudes towards reading. The data obtained from the reading attitude scale were analyzed quantitatively using SPSS 22.0.

\section{Result}

The findings of the study showed that there was a significant positive change in the students' attitudes towards reading by the end of the study, $p<0.001$. According to these results, the students were more willing to read after the implementation process as they found reading more useful. On the other hand, the value that the students gave to reading also significantly increased by the end of the study and their reading anixiety levels decreased accordingly.

\section{Discussion and Conclusion}

The results of the study revealed that the students' attitudes toward reading changed in a positive way at the end of the study. Depending on these results, it can be concluded that technology integration is essential in foreign language learning.

Since the information and communication technologies have great impact on human life, new learning areas such as technology and communication skills are being discussed among educators today. Therefore, it is important that the teaching materials to be prepared for today's students, who are highly skilled in technology, should be technology-integrated to promote communication and interaction, and encourage authentic learning.

Educators are often unable to overcome the interest in technology and direct students to study, especially outside the classroom, no matter how hard they try. Therefore, designing technology-based learning environments is essential in foreign language contexts. This study has shown that blog-based activities, when designed as an extracurricular application, have a positive effect on students' attitudes towards reading. With a further research, the impact of blogs on in-class learning can be explored. A similar research can also be conducted with the participation of basic language users so that the impact of blogs on attitudes towards reading can be explored at different proficiency levels.

\section{GİRIŞ̧}


Alımlayıcı dil becerilerinden olan okuma birçok insanın düşündüğü gibi yalnızca yazınsal bir metindeki sözcükleri tanımaya dayalı basit bir eylem değildir. Okuyucu, okuduğu metni zihninde etkin bir yapılandırma sürecine tabi tutarak anlamlandırır. Örneğin; "Ciğerimiz yanıyor!”, "Geleceğimiz kül olmasın!”, "Ellerinle yaktı̆̆ını gözyaşınla söndüremezsin!” gibi ifadelerle aslında anlatılmak istenen, bu ifadelerde yer alan sözcükleri tanımanın çok ötesindedir. Okuyucular olarak televizyonda, reklam panolarında ya da uyarı levhalarında görmeye alış1k olduğumuz bu ifadelerin orman yangınlarına karşı farkındalık oluşturmak ve insanları bilinçlendirmek amacıyla yazıldığını hepimiz biliriz. $O$ halde okuma, düşünme ve anlama eylemlerini de kapsayan karmaşı1k bir süreçtir.

Türk Dil Kurumu'na ait Türkçe Sözlük’te (TDK Büyük Türkçe Sözlük) okumak, “1. Bir yazıyı meydana getiren harf ve işaretlere bakıp bunları çözümlemek veya seslendirmek. 2. Yazılmış bir metnin iletmek istediği şeyleri öğrenmek." olarak tanımlanmaktadır. Geçmişten bugüne okuma için yapılmış birçok tanımın ortak noktası, okumanın anlama ve etkileşimi beraberinde getiren bir süreç olduğudur (Alderson ve Urquhart, 1984, ss. xviii-xix; Durkin, 1989, s. 7). Bu süreçte okuyucular, metin ile etkileşim halinde okuduğunu anlamlandırmaya çalışan etkin aktörlerdir (Silberstein, 1994, s. 6).

Anlama okumanın temel amacidır. Anlama olmadan yapılan eylem yazılı sembolleri seslendirmekten öte geçmeyecektir. Anlamanın gerçekleşmesinde okuyucunun geçmiş bilgi ve deneyimleri önemli rol oynar. İnsan zihninde şema olarak adlandırılan ve geçmiş bilgi ve deneyimlerimizi kapsayan bir genel dünya bilgisi mevcuttur. Şema ne kadar zengin ve iyi kurgulanmış olursa kavrama da o kadar kolay ve çabuk olur (Gunning, 2014, ss. 366-367). Bu bağlamda okuma, okuyucunun okuma yoluyla elde ettiği yeni bilgiyi geçmiş deneyimleriyle ilişkilendirerek zihninde anlamlandırması süreci olarak tanımlanabilir.

Okuma, bilgiye ulaşmanın temel aracı olması yönüyle önemlidir. Öğretimin tüm kademelerinde öğrenme büyük ölçüde okuma yoluyla gerçekleşmektedir. Bu yüzden, yaşam boyu öğrenme becerilerinin bir ihtiyaç halini aldığı çağdaş eğitim sisteminde öğrenmenin sürdürülebilirliği açısından okumanın alışkanlık haline getirilmesi gerekmektedir. Okuma alışkanlığı ile kişinin okumayı bir gereksinim olarak algılayarak yaşam boyu sürekli ve düzenli biçimde okuma eylemini gerçekleştirmesi kastedilmektedir (MEB, 2007, s. 1). Okuma alışkanlığı bilgiyi edinme, anlama ve değerlendirme gibi eylemleri, buna bağlı olarak da kişinin düşünce ve davranış biçimlerini etkilemesi bakımından erken yaşlardan itibaren kazanılması gereken çok önemli bir beceridir.

Yabancı dillerin öğretimi bağlamında okuma-anlama becerisinin ve akıcı okuyabilmenin dil öğrenenlere sağladığı çok sayıda avantajından bahsetmek mümkündür. Dil bilgisi kurallarını öğrenebilmenin yanı sıra, sözcük öğrenimi de büyük ölçüde okuma yoluyla gerçekleşir. Hedef kültüre ait ögelerin öğrenilmesi ve okulda öğrenilenlerin pekiştirilmesi de büyük ölçüde okuma yoluyla gerçekleşir (Day, 1993, s. ix).

"Okuma" kavramı ile yalnızca yazılı sembolleri keşfetmek olan temel okuma değil, aynı zamanda kişinin mevcut bilgi ve deneyimleriyle metni anlama ve zihinde yapılandırma süreci de vurgulanmaktadır. Bu yönüyle okuma, beynin görme, algılama, seslendirme, anlama, yapılandırma gibi işlevlerini de kapsayan çok yönlü işlevsel bir süreçtir (Durmuş, 2013, s. 185). Bu bakış açısıyla, ideal bir okuma öğretiminin iki temel amacından söz etmek mümkündür. Bunlardan ilki, etkili bir okuma deneyimi için gereksinim duyulan teknik bilgi ve becerilerin öğretilmesi, diğeri ise okumaya yönelik olumlu tutumların kazandırılmasıdır (Sainsbury, 2004, s. 49). Tutum, kişinin bilgi, deneyim, duygu ve güdülerine dayanarak kendisine ya da çevresindeki nesne ve toplumsal konu ya da olaylara karş1 zihinsel, duygusal ve davranışsal tepki verme eğilimidir. Tutumlar olumlu ya da olumsuz olabileceği gibi bilgi, deneyim, duygu ve güdüler değiştikçe tutumlar da değişir (İnceoğlu, 2011, ss. $22,23)$.

Öğrencilerin okumaya karşı tutumları onların okuma performanslarını etkileyen önemli bir etkendir (Lipson ve Wixson, 2013, s. 52). Okuma konusunda gerekli teknik bilgi ve becerilere sahip olsalar da okumaya yönelik olumsuz tutumlar okuma-anlama başarısını da olumsuz etkileyecektir (Türker, 2018, s. 7). Sürekli hissedilen başarısızlık algısı, öğrencilerde öğrenilmiş çaresizlik hissinin ortaya çıkmasına ve okumaya karşı ilgisinin azalmasına neden olabilir (Jennings, Caldwell, ve Lerner, 2006, s. 3; Lipson ve Wixson, 2013, s. 53). Bu nedenle, okuma öğretiminin ilk aşaması öğrencileri başarılı olacakları konusunda ikna etmek, bir sonraki aşaması ise öğrencileri ödüllendirmek olmalıdır (Carnine, Silbert, Kame'enui, Tarver, ve Jungjohann, 2006, s. 18). 
Öğrenme ve öğretme süreçlerinin tasarlanmasında öğretim programının amaçları, başarı ölçütleri, hedef kitle ve öğretim malzemeleri gibi çok sayıda değişkenin varlığından söz edilebilir. Eğitim programlarının ve öğretim yöntemlerinin belirlenmesinde etkili olan tüm bu değişkenlerin yanı sıra eğitimciler tarafından görüş birliğine varılan ve değişmez olarak kabul edilen ortak konu eğitimin öğrenci merkezli olması gerektiğidir. Öğrenci merkezli eğitimde vurgu öğrencidedir. Eğitimde yeni değerler akademik becerilerin yanı sıra öğrenmenin bireyselliğini ön plana çıkaran düşünmeyi öğrenme, bilgi üretme, problem çözme, bireysel çalışma, benlik gelişimi ve sağlıklı iletişim gibi becerilerin de öğrencilere kazandırılmasını öngörmektedir. Öğrenen ve öğreten rollerinin değiştiği bu süreçte öğrenci bilgiye ulaşan, elde ettiği bilgiyi kullanarak problem çözen ve yeni bilgiler üreten; öğretmen ise bir takım çalıştırıcısı gibi öğrencilerin kapasitelerini en üst düzeye taşımak için çabalayan etkin bireylerdir (Özden, 2008, ss. 67, 78-79).

Öğrenciyi merkeze alan bir eğitim yapılandırma sürecinde yerine getirilmesi gereken ön koşul öğrenci ilgi ve ihtiyaçlarının belirlenmesidir. Teknolojiyle iç içe yaşayan ve ileri düzeyde teknoloji kullanma becerilerine sahip olan günümüz öğrencilerine yönelik bir öğrenme ortamı tasarlarken teknolojik altyapıdan yararlanılmaması düşünülemez. Teknoloji, öğrenmeyi okul sınırları dışına taşımanın ve öğrenmeyi bireyselleştirmenin en etkin yoludur. Özellikle bilgi ve iletişim teknolojilerinde baş döndürücü bir hızla yaşanan gelişmeler ve bilgisayarla yapılabilen birçok işlemin mobil cihazlar üzerinden yapılabilir duruma gelmesi teknoloji tabanlı öğretim yöntemleri ve öğrenme malzemeleri geliştirmeyi adeta zorunlu kılmıştır.

Eğitimde teknoloji kullanımının temel gerekçesi Mayer'in (2009, s. 4) “Çoklu Ortam Teorisi” ile açıklanmaktadır. Çoklu ortamlar, bilginin ses, görüntü, animasyon, video, gibi ögelerle birleştirilerek çeşitli araçlar ve yöntemler aracılığıyla sunulduğu ortamlardır. Bu teoriye dayanarak, öğrenme ortamlarının ve öğretim malzemelerinin tasarlanma sürecinde üzerinde durulması gereken en önemli konu olabildiğince fazla duyu organlarına hitap ederek farklı algıların harekete geçirilmesini sağlamaktır. Tasarlanan malzemeler ne kadar çok duyuya hitap ederse öğrenme de aynı oranda etkin ve kalıc1 olacaktır (Özmen, 2013, s. 68).

Çoklu ortam teorisine bağlı olarak ortaya çıkan çoklu ortamlı öğrenme kavramı ise bilgi ve iletişim yazılımlarının eğitim ortamında kullanımı sonucu ortaya çıkan öğretim uygulamalarının genel adıdır. Bilgi ve iletişim teknolojilerinin öğretim sürecine katkıları aşağıdaki gibi özetlenebilir:

- Etkin ve bağımsız öğrenme yaşantılarına imkân verir.

- Bireysel öğrenmeye olanak tanır (seviye, ilgi ve anlama güçlüğüne bağlı olarak)

- Okul içi ve okul dış1 öğrenmeyi destekler (Alev, 2013, s. 18).

Bilgi ve iletişim teknolojileri bilgi edinmeyi, bilgiyi depolamayı ve iletmeyi sağlayan bilgisayar ve iletişim teknolojilerinin genel adıdır. Eğitim uygulamaları açısından değerlendirildiğinde bilgisayarlar, ses ve video oynatıcılar, sunu araçları, akıllı tahtalar, Web 1.0, Web 2.0, Web 3.0 araçları ve mobil cihazlar gibi çok çeşitli araçlar öğrenme ve öğretme süreçlerinin daha etin yürütülebilmesi amacıyla önemli faydalar sağlamaktadır.

Bilgi ve iletişim teknolojilerinin öğretim sürecine en önemli katkılardan biri özgün öğrenme ortamları oluşturulmasına ve öğretmenler kadar öğrencilerin de görüşlerine değer vererek onların öğrenme sürecine etkin katılımına olanak sağlamasıdır. Bilgi ve iletişim teknolojileri ile öğrenme sürecini tasarlarken öğretmeni teknoloji ile yer değiştirmenin bir işe yaramayacağı unutulmamalıdır. Böyle bir ortamda öğretmenler öğrenmeyi sağlayan değil, teknolojiden faydalanarak öğrenmeyi kolaylaştıran bireylerdir (Robinson, Molenda, ve Rezabek, 2008, s. 41). Eğitim bir davranış değiştirme bilimiyse bu değişimin hızlı, etkili ve yaşam ile ilişkili olması gerekir (Ceyhan, 2007, s. 49). Bu da ancak, bilgi toplumunda yaşadığımız şu günlerde bilgi ve iletişim teknolojileri kullanılarak mümkün olabilir.

Hayatın her alanında olduğu gibi eğitimde de büyük değişimlerin öncüsü olan bilgi ve iletişim teknolojileri, internetin bugün kolay ulaş1labilir hale gelmesiyle yeni yöntem ve uygulamaların, buna bağlı olarak da yeni öğrenme biçimlerinin ortaya çıkmasına neden olmuştur. Web araçları olarak da bilinen internet tabanlı bu uygulamaların eğitime katkılarından bazıları içeriğe zaman ve mekândan 
bağımsız, kolay ve hızlı erișebilme imkânı sağlaması, bilgiyi güncelleyebilmek ve güncel ve geçerli bilgiye ulaşabilme olanağı sunması, ekonomik olması ve kullanıcıların içerikle ve diğer kullanıcılarla çok yönlü etkileşimini sağlaması olarak sıralanabilir (Çoklar, 2014, ss. 232-233).

İnternet teknolojilerinin ortaya çıkmasıyla birlikte yeni bir çağ başlamış ve her geçen gün internet alanında yaşanan gelişmelere yenileri eklenmiştir. Bugüne gelindiğinde üç dönemde ele alınabilecek olan internetin ilk dönemlerine Web 1.0 teknolojileri (1994-2004) ad1 verilmektedir. Web 1.0 teknolojileri, pasif alıcı konumunda olan internet kullanıcılarının Web'de var olan bilgiyi okuyabildikleri ve dilediklerinde bilgisayarlarına indirebildikleri internet araçlarıdır. İnternet teknolojisinin gelişmesi ve insanlar arasında etkileşim ihtiyacının artmasıyla Web 2.0 araçları ortaya çıkmışıı. Web 2.0 araçları web'de sunulan bilgiyi elde etmenin yanında insanların aktif olarak birbirleriyle iletişim kurabildikleri, bilgi ve deneyimlerini paylaşabildikleri ve kendi düşüncelerini özgürce ifade edebildikleri ortamlardır. Web 2.0 araçları sayesinde internet kullanıcıları tüketici konumundan çıkarak kendi içeriklerini üretebilir ve başkalarıyla paylaşabilir duruma gelmiştir. Bugün ise etkileşimin ve paylaşımın sadece insanlar arasında değil yapay zekâya sahip bilgisayarlar ile de gerçekleşebildiği teknolojiden bahsedebildiğimiz bir dönemin içerisindeyiz. Web 3.0 teknolojileri olarak adlandırılan bu araçlar internet kullanıcılarının ilgi ve ihtiyaçlarını yorumlayarak kişiye özel çözümler sunabilmektedir (Altun, 2013, ss. 218-221).

Mobil teknolojilerin hemen herkes tarafından etkin kullanıldığg günümüzde, Web 2.0 araçları özellikle teknoloji çağının içine doğan ve "z kuşağı" olarak adlandırılan gençlerin yaşamında büyük yer tutmaktadır. Web 2.0 araçları, kullanıcıların kendi içeriklerini geliştirmelerine ve bu içeriği diğer kullanıcılarla paylaşmalarına olanak sağlayan, böylelikle sosyal etkileşimi öne çıkaran yapısıyla (Warschauer, 2011, s. 36) eğitimde de geniş uygulama alanlarına sahiptir. Öğrenmeyi okul sınırları dışına taşıma, etkileşimli ve işbirlikli öğrenme ortamları tasarlama, öğrenmeyi bireyselleştirme gibi avantajlar sunan bu teknolojiler eğitimin her kademesinde ilgi çeker duruma gelmiştir. Web 2.0 araçlarından bazıları şunlardır (İşman, 2011, ss. 496-516):

1. Bloglar: Bireyler ve kurumların haber, tematik konular ya da kişisel deneyimler hakkındaki yazılarını başkalarıyla paylaşmak için yayınladıkları çevrimiçi sitelerdir.

2. Vikiler: İçeriğin kullanıcılar tarafından değiş̧tirilebildiği, çevrimiçi ansiklopedi işlevi görevi gören Web sayfaları topluluğudur.

3. Sosyal İşaretleme: Web kaynaklı bir bilginin önerilmesi esasına dayanan ve içeriğin değil içeriğe ait bağlantı ya da kaynağın paylaşıldığ 1 bir servistir.

4. Sosyal A $\breve{g}$ Servisleri: Ortak ilgi alanlarına sahip insanların birbirleriyle iletişimini sağlayan çevrimiçi ortamlardır.

5. Mikrobloglar: Sınırlı yazı karakterine sahip ve sınırlı dosya paylaşma alanı sunan web servisleridir.

6. Podcastler: Taşınabilir müzik çalar ve video göstericiler üzerinden çevrimdışı olarak oynatılabilen görsel veya sözel medya dosyalarıdır.

Web 2.0 araçlarını yabancı dil öğretimine uyarlama çabalarının arkasında, ders saatleriyle sınırlandırılmış geleneksel öğrenme ortamlarının aksine vikiler, bloglar, eşzamanlı ve eşzamansız iletişim araçları gibi web teknolojileri sayesinde tüm öğrencilerin dili eşit kullanım imkânına sahip olması gibi nedenler yatmaktadır (Blake, 2008, s. 134). Teknoloji, öğrenme biçimimizi değiştirirken bir takım yan etkileri de beraberinde getirmektedir. Bilgiye ulaşmanın temel aracı olan (Aytan, 2015, s. 2) ve en önemli dil becerilerinden sayılan okumaya (McDonough ve Shaw, 1993, s. 101) karş1 ilgi giderek azalmakta, öğrenciler kitaplar yerine zamanlarının büyük bölümünü akıllı ekranlar karşısında geçirmektedirler. "Z kuşağı" olarak nitelendirilen bugünün öğrencilerini teknolojiye olan ilgilerinden uzaklaştırmadan okumaya yönlendirmek eğitimciler arasında uzun zamandır tartışılan konulardan biri olmuştur. Avrupa Ortak Öneriler Çerçevesinde de belirtildiği gibi, dil öğrenmenin dili kullanabilme yetisiyle açıklandığı (Avrupa Konseyi, 2013, s. 18) modern dil öğretiminin ilkeleri ve "z kuşağının" ilgi 
ve eğilimleri dikkate alındığında bu sorunun web 2.0 teknolojilerinden biri olan bloglar aracılığıyla çözümlenebileceği düşünülmüştür.

Öğrenme ve öğretme sürecinde sosyal etkileşim eğitim teorilerinin kilit taşı niteliğindedir (Hokanson ve Long, 2012, s. 4). Kod yazma gibi teknik bilgi gerektirmeyen ve kullanıcıların basit bir şekilde üye olarak ses, resim, yazı ve videolarını diğer internet kullanıcıları ile paylaştıkları web sayfaları olan bloglar (Çoklar, 2014, s. 225) öğretmen ve öğrencilerin sınıf dışında da etkileşimine olanak sağlayarak yeni öğrenme ortamları oluşturur.

Yabancı dillerin öğretiminde blog kullanımı ile ilgili bugüne dek yürütülmüş çok sayıda çalışmaya rastlamak mümkündür. İlgili alanyazın incelendiğinde bu çalışmaların büyük çoğunluğunun İngilizce başta olmak üzere farklı dillerin öğretimi ile ilgili olduğu ve genellikle yazma becerisi öğretiminde blog etkisini araştırmak amacıyla tasarlandığı görülmektedir (Ackerman, 2006; Arslan ve Şahin-K1z1l, 2010; Chang, 2016; Fellner ve Apple, 2006; Hashemi ve Najafi, 2011; Huang, 2016; Kazanc1, 2012; Kennedy, 2003; Lin, 2012; Noytim, 2010; Özdemir, 2015; Sun, 2010; Vurdien, 2012; Wu, 2015). Yabancı dil olarak Türkçe öğretiminde ise blog uygulamaları ile ilgili sınırlı sayıda çalışma olmakla birlikte okuma becerisi öğretimi bağlamında henüz kapsamlı bir çalışmaya rastlanmamaktadır. Bu çalışma ile elde edilen verilerin alan yazına katkı sağlayacağı düşünülmektedir.

Yabancı dil öğretimi ile ilgili yürütülen birçok araştırmanın ortak sonucu, öğrenme sürecinin öğrenen odaklı olarak yapılandırılması gerektiği yönündedir. Avrupa Ortak Öneriler Çerçevesinde de belirtildiği üzere dil öğreniminin temel amacı iletişimsel görevler yerine getirebilmek için dili kullanabilme yetisine sahip olabilmek olmalıdır. Öğrenen merkezli bir eğitim anlayışında hedef dilin kullanılabileceği iletişimsel öğrenme ortamları tasarlamak amacıyla eğitimciler, program geliştirenler ve materyal tasarımcılar yoğun çaba harcamaktadır. İleri düzeyde teknoloji okuryazarı olan günümüz öğrencilerinin iletişimsel ihtiyaçları ve öğrenme biçimleri göz önünde bulundurulduğunda söz konusu ihtiyacın bloglar aracılığıyla karşılanacağı düşünülmüş, bu amaçla araştırmacı tarafindan özgün olarak tasarlanan blog tabanlı öğretim etkinliklerinin yabancı dil olarak Türkçe öğrenenlerin okumaya yönelik tutumları üzerindeki etkisi araştırılmıştır.

\section{YÖNTEM}

Yabancı dil olarak Türkçe öğrenenlerin okumaya yönelik tutumları üzerinde blog etkisinin araştırıldığı bu çalışma kapsamında araştırmacı tarafından özgün bir blog sitesi oluşturulmuş, hazırlanan içerik karma öğrenme modelinin ilkeleri çerçevesinde bir ders dış1 etkinlik olarak uygulanmıştır. Özgün dil kullanımını teşvik edebilmek amacıyla güncel gazete haberleri ve edebi metinler kullanılarak hazırlanan etkinlikler sekiz haftalık uygulama süresince blog üzerinden öğrencilerle paylaşılmıştır. Çalışma kapsamında yanıt aranan araştırma sorusu aşağıdaki gibidir:

- Blog kullanımının yabancı dil olarak Türkçe öğrenenlerin okumaya yönelik tutumları üzerindeki etkisi nedir?

Nicel araştırma yöntemlerinin uygulandığı bu çalışmanın verileri Rashtchi ve Hajihassani (2010) tarafından geliştirilen okuma tutum ölçeğinden elde edilmiş̧ir. Elde edilen veriler ilgili araştırma sorusu bağlamında "SPSS 22.0" (Statistical Package for The Social Sciences) yazılım programı kullanılarak analiz edilmiştir.

\section{1. Çalıșma Grubu}

Çalışma, B2 düzeyinde Türkçe öğrenen 52 yabancı uyruklu öğrencinin katılımıyla yürütülmüş̧ür. Lisans ya da lisansüstü düzeyde öğrenim görmek üzere 26 farklı ülkeden Türkiye’ye gelen katılımcılara ait veriler Tablo 1'de gösterilmiştir.

Tablo 1: Çalışmanın katılımeıları 


\begin{tabular}{cccc}
\hline Özellikler & Kategoriler & $\mathbf{N}$ & $\mathbf{\%}$ \\
\hline \multirow{4}{*}{ Yaş } & $16-18$ & 7 & 13.4 \\
& $19-21$ & 23 & 44,2 \\
& $22-24$ & 12 & 23 \\
& $25-27$ & 9 & 17.3 \\
\multirow{2}{*}{ Eğitim } & $28-30$ & 1 & 1.9 \\
& Lisans & 31 & 59.6 \\
& Y. Lisans & 19 & 36.5 \\
& Doktora & 2 & 3.8 \\
\hline \multirow{2}{*}{ Cinsiyet } & Erkek & 28 & 53.8 \\
& Kadın & 24 & 46.1 \\
\hline
\end{tabular}

Çalışma kapsamında tasarlanan blog etkinliklerinin karma öğrenme modelinin ilkeleri esas alınarak ders dışı uygulanması ve sözlük, ders kitabı ya da dil bilgisi kitabı gibi başvuru kaynakları kullanılmadan bilgisayar ve mobil cihazlar üzerinden tamamlanacak olması gibi nedenlerle bağımsız kullanıcılar olan B2 düzeyindeki öğrenciler çalışma için uygun görülmüştür.

\subsection{Veri Toplama Araçları}

Blog kullanımın okumaya yönelik tutumlar üzerindeki etkisinin araştırıldığı çalışmada kullanılmak üzere araştırmacı tarafından öncelikli olarak özgün bir blog sitesi tasarlanmış ve yine özgün olarak hazırlanan içerik bir ders dışı etkinlik olarak blog sitesinde paylaşılmıştır. Nicel araştırma yönteminin uygulandığı çalışmanın verileri ise çalışma öncesi ve çalışma sonrası uygulanan okuma tutum ölçeğinden elde edilmiştir.

Okuma becerisine yönelik etkinliklerin bir ders dışı uygulama olarak paylaşıldığı blog sitesi için "Blogger" altyapısı tercih edilmiştir. Toplamda dört bölümden oluşan bloğun ilk bölümü olan Medya sayfasında, Türkiye'de yayın yapan ulusal gazetelerin internet sitelerinden alıntılanan güncel haber metinleri ve bu metinlerle ilgili hazırlanmış okuma-anlama etkinlikleri yer almaktadır. Metin seçiminde dikkat edilen en önemli husus herhangi bir siyasi görüş, etnik düşünce ya da dini inanç ögeleri içermeyen; gazetelerin teknoloji, bilim, kültür, sanat, tarih, eğitim ve spor sayfalarından alıntılanan haberlerin tercih edilmiş olmasıdır. Blogda kullanılan haber metinlerinin düzeye uygunluğunun belirlenebilmesi amacıyla yabancılara Türkçe öğreten iki okutman ve B2 düzeyinde Türkçe öğrenen 6 öğrencinin görüşlerine başvurulmuş ve gerekli görülen değişiklikler yapılmıştır. Paylaşılan haber ile ilgili farklı haber sitelerine ait bağlantı adresleri, haberle ilgili görseller ve haberin videosu da daha fazla okumayı teşvik etmek amacıyla ilgili sayfada paylaşıımıştır. Ayrıca, ders dışı etkileşimi sağlayabilmek amaciyla haberin sonuna bir tartışma sorusu eklenmiş, öğrencilerin konuyla ilgili görüşlerini Yorum bölümünde paylaşmaları istenmiştir. Böylelikle, hedef dilde iletişim kurabilme olanağına sahip olan öğrencilerin aynı zamanda akran geribildirimi alarak farklı bakış açılarından eleştirel düşünebilmelerine imkân sağlanmıştır.

Bloğun ikinci bölümü olan Öykü Kitaplığı bölümünde, ünlü Türk edebiyatçıları tarafından kaleme alınmış öyküler yer almaktadır. Öykülerin seçiminde iki ölçüt dikkate alınmıştır. Bu ölçütlerden biri öykülerin kavramsal yoğunluğu, diğeri ise öykülerin uzunluğudur. Uygulama bir ders dışı etkinlik olarak tasarlandığı için öğrencilerin ilgilerini kaybetmeden okuyabilecekleri, uzunluğu 3-10 sayfa arasında değişen öyküler tercih edilmiştir. Öyküler taşınabilir cihazlar üzerinden okunabilir biçimde düzenlenmiştir. Böylelikle, öğrencilere tablet bilgisayar ve akıllı telefonlarını kullanarak diledikleri yerden ve diledikleri zaman öyküleri okuma imkânı sağlanmıştır.

Çalışma karma öğrenme modelinin ilkeleri doğrultusunda bir ders dışı uygulama olarak tasarlandığından ve herhangi bir kaynak kitap kullanımını gerektirmediğinden öğrencilerin ihtiyaç halinde başvurabilecekleri bir sözlük sayfası hazırlanarak bloğa eklenmiştir. Bloğun üçüncü bölümünü oluşturan Sözlükler sayfası toplamda 12 dilde Türkçe çeviri yapabilen çevrimiçi sözlük sitelerinin 
bağlantı adreslerini içermektedir. Bloğun son bölümü ise, uygulama süresince blogda yapılan paylaşımlara ait bildirimlerin ve gerekli diğer tüm bilgilendirmelerin yapıldığı Duyurular sayfasıdır.

Blog sitesinin tema seçimi, sayfa düzeni ve görünüm ayarları gibi teknik özellikleri ile içeriğinin değerlendirilebilmesi amacıyla uzman görüşüne başvurulmuş ve gerekli düzenlemeler tamamlanarak tasarım aşaması tamamlanmıştır. Blog sitesinin ana ekran görüntüsü Şekil 1'de gösterilmektedir.

Şekil 1: Blog sitesi ana ekran görüntüsü

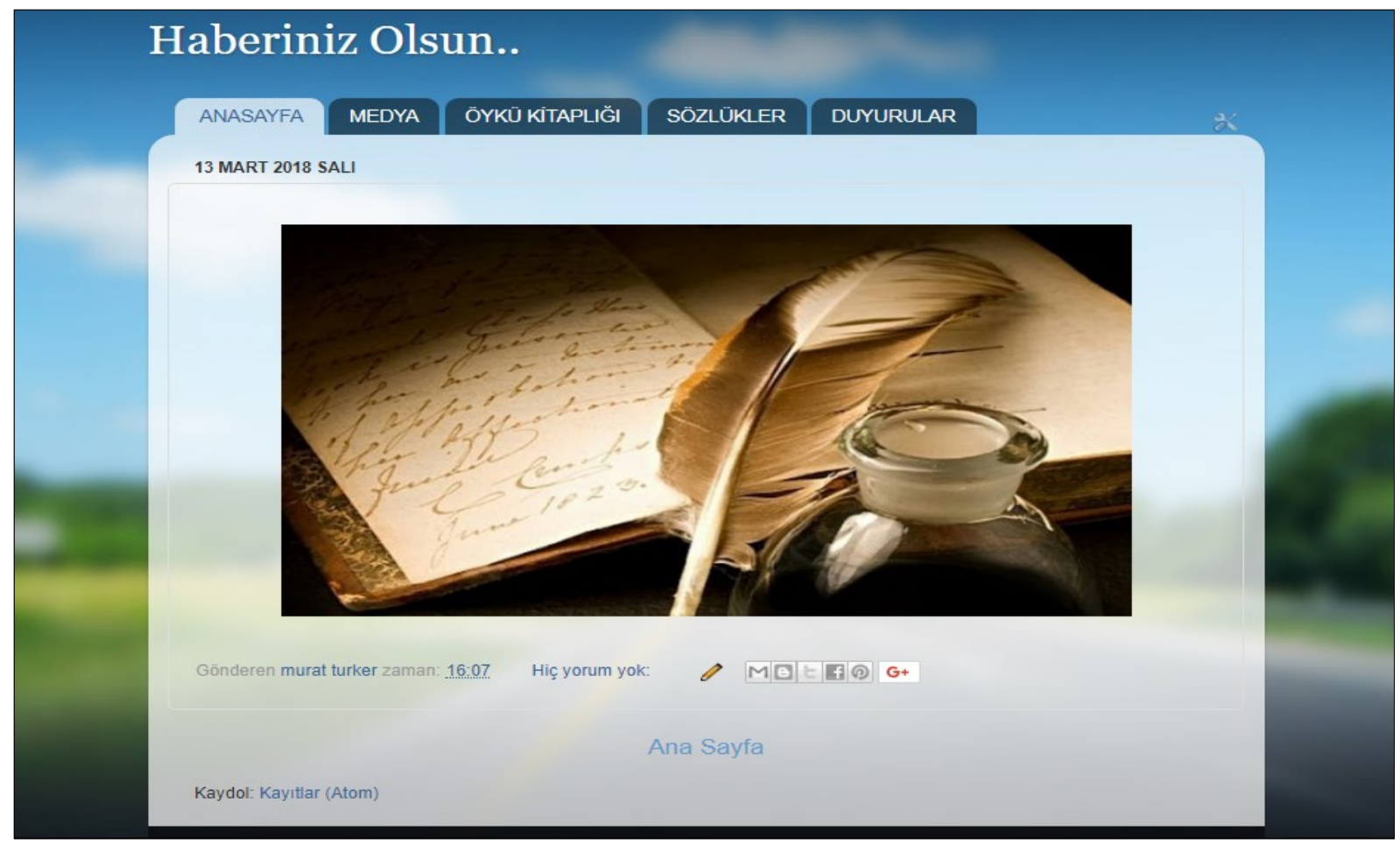

Katılımcıların okumaya yönelik tutumlarını belirleyebilmek amacıyla okuma tutum ölçeği kullanılmıştır. Özgün dili İngilizce olan ölçeği Türkçeye uyarlama sürecinde ölçek çeviri yöntemlerinden geleneksel yaklaşım tercih edilmiştir. Likert tipi hazırlanan ve 30 maddeden oluşan ölçeği Türkçeye uyarlama süreci tamamlandıktan sonra B2 düzeyinde Türkçe öğrenen 89 yabanc1 uyruklu öğrenciyle bir pilot çalışma yapılmış, anlaşılması güç ifadeler yabancılara Türkçe öğreten iki okutmanın görüşleri de alınarak gözden geçirilmiştir. Pilot çalışmadan elde edilen verilerle araştırmacı tarafından ölçeğin güvenirlik ve faktör analizleri yapılmıştır. Varimax döndürme yöntemiyle yapılan analiz sonuçlarına göre dört faktörlü bir yapıya sahip olduğu belirlenen ölçeğin Cronbach Alfa güvenirlik katsayısı $\alpha=0.916$ olarak hesaplanmış ve ölçeğin oldukça güvenilir olduğu tespit edilmiştir.

\subsection{Uygulama Süreci}

Blog kullanımın yabancı dil olarak Türkçe öğrenenlerin okumaya yönelik tutumları üzerindeki etkisinin araştırıldığı bu çalışmanın uygulama süreci sekiz hafta olarak planlanmıştır. Çalışma öncesinde bir tanıtım toplantısı düzenlenerek katılımcılara bloglar hakkında bilgiler verilmiş ve uygulama süreci anlatılmıştır. Uygulama süresince her hafta blog üzerinden belli aralıklarla iki haber metni ve iki öykü paylaşılmış, aynı uygulama sekiz hafta boyunca devam etmiştir. Bu süre zarfinda ögrenciler mevcut sınıf içi müfredat takibini sürdürdükleri için blog paylaşımlarının ders saatleri dışında yapılmasına dikkat edilmiştir.

Bu çalışma, yapısı gereği yarı deneysel bir araştırma desenine sahip olup, tek gruplu ön test-son test modeli' ne göre tasarlanmıştır. Katılımcıların okumaya yönelik mevcut tutumlarının belirlenebilmesi amacıyla okuma tutum ölçeği çalışma öncesinde uygulanarak ön-test verileri elde edilmiştir. Sekiz haftalık uygulama sürecinin ardından aynı ölçek tekrar uygulanarak son-test verileri elde edilmiştir. Çalışma öncesi ve çalışma sonrasında okuma tutum ölçeği kullanılarak elde edilen tüm 
veriler "SPSS 22.0" programı ile analiz edilerek blogların okumaya yönelik tutumlar üzerindeki etkisi incelenmiştir.

\section{BULGULAR}

Blogların, bir ders dışı öğrenme ortamı olarak uygulandığında yabancı dil olarak Türkçe öğrenenlerin okumaya yönelik tutumları üzerindeki etkisinin araştırıldığı bu çalışmanın verileri Rashtchi ve Hajihassani (2010) tarafından geliştirilen ve araştırmacı tarafından Türkçeye uyarlanan okuma tutum ölçeğinden elde edilmiştir. Okumaya yönelik tutumların istek, fayda, kaygı ve değer algısı olarak dört boyutta ele alındığı ölçek, öğrencilerin okumaya yönelik mevcut tutumlarını belirleyebilmek amaciyla çalışma öncesinde ve uygulama sonunda öğrencilerin tutumlarında anlamlı bir değişim olup olmadığını belirleyebilmek amacıyla çalışma sonrasında olmak üzere iki kez uygulanmıştır. Okuma tutum ölçeğinden elde edilen verilerle ilgili istatistiksel işlemlere başlamadan önce verilerin normal dağılıp dağılmadıkları test edilmiş, normal dağılım gösterdiği belirlenen verilerin analizi için parametrik istatistik yöntemleri kullanılmıştır. Her iki ölçekten elde edilen verilerin aritmetik ortalamaları ve standart sapmaları Tablo 2'de görülmektedir.

Tablo 2: Okuma tutum ölçeği betimsel istatistik verileri

\begin{tabular}{|c|c|c|c|c|c|}
\hline & Madde & $\bar{x}$ & $\mathbf{N}$ & Ss & $\mathbf{S} \bar{x}$ \\
\hline \multirow{5}{*}{$\begin{array}{l}\text { Uygulama } \\
\text { Öncesi }\end{array}$} & İstek & 2.60 & 52 & 0.42112 & 0.058 \\
\hline & Fayda & 3.02 & 52 & 0.41717 & 0.057 \\
\hline & Kayg1 & 2.37 & 52 & 0.44395 & 0.061 \\
\hline & Değer Algis1 & 3.06 & 52 & 0.35355 & 0.049 \\
\hline & OTÖ Toplam & 2.76 & 52 & 0.25639 & 0.035 \\
\hline \multirow{5}{*}{$\begin{array}{l}\text { Uygulama } \\
\text { Sonras1 }\end{array}$} & İstek & 3.44 & 52 & 0.36511 & 0.050 \\
\hline & Fayda & 3.45 & 52 & 0.39482 & 0.054 \\
\hline & Kayg1 & 3.19 & 52 & 0.30803 & 0.049 \\
\hline & Değer Algisı & 3.40 & 52 & 0.35262 & 0.048 \\
\hline & OTÖ Toplam & 3.37 & 52 & 0.29340 & 0.040 \\
\hline
\end{tabular}

Tablo 2'deki sonuçlar incelendiğinde, öğrencilerin uygulama öncesi ve uygulama sonras1 okumaya yönelik tutumlarında belirgin farklılıklar olduğu görülmektedir. Her iki ölçek arasındaki bu farkın istatistiksel açıdan anlamlı olup olmadığının belirlenebilmesi amacıyla İlişkili Örnekler için Ttesti (Paired Samples T-test) kullanılmış, anlamlılık düzeyi 0.05 kabul edilerek sonuçlar yorumlanmıştır (Bkz. Tablo 3).

Tablo 3: Okuma tutum ölçeği (önce \& sonra) ilişkili örnekler için t-testi sonuçları

\begin{tabular}{ccccccc}
\hline & $\overline{\mathrm{X}}$ & $\mathbf{S s}$ & $\mathbf{S} \overline{\mathrm{x}}$ & $\boldsymbol{t}$ & $\mathbf{S d}$ & $\boldsymbol{p}$ (iki ÿ̈nlü) \\
\hline İstek_1 - İstek_2 & -0.83940 & 0.52959 & 0.07344 & -11.430 & 51 & 0.000 \\
Fayda_1 - Fayda_2 & -0.42549 & 0.55590 & 0.07709 & -5.519 & 51 & 0.000 \\
Kayg1_1 - Kayg1_2 & -0.81908 & 0.55051 & 0.07634 & -10.729 & 51 & 0.000 \\
Değer_1 - Değer_2 & -0.34452 & 0.44475 & 0.06168 & -5.586 & 51 & 0.000 \\
OTÖ_1-OTÖ_2 & -0.60712 & 0.41025 & 0.05689 & -10.672 & 51 & 0.000 \\
\hline
\end{tabular}


Tablo 3'deki veriler incelendiğinde, okuma tutum ölçeğinden uygulama öncesi ve uygulama sonrası elde edilen veriler arasında anlamlı bir fark olduğu, sekiz haftalık uygulama sonunda, öğrencilerin okumaya yönelik tutumlarında olumlu yönde anlamlı bir değişim olduğu görülmektedir, $p$ $<0.001$. Bu sonuçlara göre, uygulama öncesine kıyasla uygulama sonunda öğrencilerin okumaya karş1 daha istekli olduğu yönünde anlamlı bir fark görülmektedir, $p<0.001$. Ölçeğin ikinci boyutu olan, öğrencilerin okumanın faydaları ile ilgili görüşlerinde de uygulama sonunda olumlu yönde değişimler olduğu ve bu değişimlerin anlamlı olduğu görülmektedir, $p<0.001$. Ölçekte kaygı düzeyinin ölçüldüğü maddelerden elde edilen sonuçlar ise, öğrencilerin uygulama sonunda okumaya yönelik kaygı düzeylerinin anlamlı oranda azaldığını ortaya koymuştur, $p<0.001$. Bununla birlikte, öğrencilerin okumaya verdikleri değerin de uygulama sonunda anlamlı oranda arttı̆̆ göze çarpmaktadır, $p<0.001$.

\section{TARTIŞMA, SONUÇ ve ÖNERILER}

Günlük yaşamlarında dahi teknolojiyle iç içe olan; iletişim biçimleri, eğlence anlayışları, sosyal ilişkileri ve araştırma yöntemleri bağlamında önceki nesillere göre bir hayli farklılık gösteren dijital neslin öğrenme biçimlerinde de farklılıklar olması gerektiğini tahmin etmek güç olmayacaktır. Günümüz öğrencilerinin değişen ilgi ve algıları ile sahip oldukları teknolojik imkânlar bilgiyi edinme, değerlendirme ve başkalarıyla paylaşmada yeni yolların ortaya çıkmasına neden olmuştur. En önemli dil becerilerinden sayılan ve bilgiye ulaşmanın temel aracı olarak görülen okuma ise bugünlerde ihmal edilir olmuş, teknolojik araçlarla çoklu ortamlı öğrenme ön plana çıkarak ilgi çeker hale gelmiştir.

Geleneksel yöntemlerle gerçekleştirilen dil öğretiminin günümüz öğrencilerinin ilgi ve ihtiyaçlarını karşılamada yetersiz oluşu, ayrıca çağdaş eğitim anlayışında benimsenen özgün öğrenme, eleştirel düşünme, işbirlikli ve etkileşimli öğrenme ve iletişim gibi becerilerin geleneksel öğretimle ders saatleri içerisinde kazandırılmasının pek mümkün olmadığı düşünüldüğünde, teknoloji destekli yeni öğretim yöntemlerinin geliştirilmesi de bir gereksinim halini almıştır. Bu bağlamda, farklı algıları harekete geçiren ve öğrenmeyi okul sınırları dışına taşıyarak iletişimi ve etkileşimi ön plana çıkaran Web 2.0 araçları yabancı dil öğretiminde geniş uygulama alanları bulmaktadır. Bu çalışmada, Web 2.0 araçlarından biri olan blogların yabancı dil olarak Türkçe öğrenenlerin okumaya yönelik tutumları üzerindeki etkisi araştırılmış, bu amaçla araştırmacı tarafından özgün bir blog sitesi tasarlanarak hazırlanan içerik bir ders dişı etkinlik olarak uygulanmıştır.

Çalışmanın verileri, uygulama öncesinde ve sekiz haftalık uygulama sonrasında olmak üzere iki kez uygulanan okuma tutum ölçeğinden elde edilmiştir. Nicel analiz yöntemleriyle elde edilen sonuçlar öğrencilerin okumaya yönelik tutumlarında olumlu yönde anlamlı bir değişim olduğunu ortaya koymuştur. Uygulama sonunda, öğrencilerin blog üzerinden gerçekleştirilen okuma etkinliklerine katılım konusunda daha istekli olduğu, okumaya yönelik kaygı düzeylerinin belirgin düzeyde azaldığ1, okumanın kişisel ve akademik gelişimlerine fayda sağladığını düşündükleri için okumaya daha fazla değer vermeye başladıkları anlaşılmıştır.

Çalışmanın sonuçları, yabancı dil öğretiminde teknoloji entegrasyonunun gerekliliğini ortaya koymaktadır. Eğitimciler ne kadar çabalasa da teknolojiye olan ilginin önüne geçip öğrencileri okumaya yönlendirmek çoğu zaman mümkün olmamaktadır. Bu sebeple, öğrenciyi merkeze alan eğitim anlayışında atılacak en önemli adımlardan birisi ögrenci ilgi ve ihtiyaçlarına uygun öğrenme ortamları tasarlamak olmalıdır. Bilgi ve iletişim teknolojilerinin insan yaşamını hızla etkisi altına alması sonucu, bugün dört temel dil beceresinin yanı sıra teknoloji ve iletişim becerileri gibi yeni öğrenme alanları ortaya çıkmıştır. Eğitimin hangi kademesinde olursa olsun, teknolojiyi kullanma eğilimleri ileri düzeyde olan günümüz öğrencileri için hazırlanacak öğretim malzemelerinin de iletişimi ve etkileşimi ön plana çıkaran, özgün öğrenmeyi teşvik eden teknoloji destekli malzemeler olması önemlidir.

Öğrenmeyi okul sınırları dışına taşıması, sosyal ortamlar olması, bilgisayarlar ve mobil cihazlar üzerinden kolaylıkla kullanılabilmesi gibi özellikleri ile bloglar etkili öğrenme ortamlarıdır. Bu çalışma, eğitim programının amaçları ve bağımsız kullanıcı düzeyindeki öğrencilerin özellikleri dikkate alınarak tasarlanan blog tabanlı etkinliklerin ders dışında uygulandığında öğrencilerin okumaya yönelik tutumlarını olumlu yönde etkilediğini ortaya koymuştur. İleride yapılacak olan benzer bir çalışmayla, blogların sınıf içi öğrenmeye etkisi araştırılabilir. Blog tabanlı öğretim malzemelerinin öğretmenin rehberliğinde sınıf içi bir etkinlik olarak uygulandığı böyle bir çalışma temel kullanıcı düzeyindeki öğrencilerle de yürütülebilir. Böylelikle, blogların okumaya yönelik tutumlar üzerindeki etkisi farklı düzeylerde araştırılabilir. 


\section{KAYNAKÇA}

Ackerman, J. D. (2006). Motivation for writing through blogs. (Yüksek Lisans Tezi), Bowling Green State University.

Alderson, J. C., \& Urquhart, A. H. (1984). Introduction: What is reading? In J. C. Alderson \& A. H. Urquhart (Eds.), Reading in a foreign language (pp. xv-xxviii). New York: Longman.

Alev, N. (2013). Öğretim teknolojisi ve öğretmen eğitimine yansımaları. In N. Yiğit (Ed.), Öğretim teknolojileri ve materyal tasarımı (5 ed., pp. 14-28). Trabzon: Celepler Matbaacılık.

Altun, T. (2013). Bilgisayar destekli öğretim araç-gereçlerinin hazırlanması ve uygulanması. In N. Yiğit (Ed.), Ögretim teknolojileri ve materyal tasarımı (5 ed., pp. 189-237). Trabzon: Celepler Matbaacılık.

Arslan, R. Ş., \& Şahin-Kızıl, A. (2010). How can the use of blog software facilitate the writing process of english language learners? Computer Assisted Language Learning, 23(3), 183-197.

Avrupa Konseyi. (2013). Diller için Avrupa Ortak Öneriler Çerçevesi Öğrenim, Öğretim ve Değerlendirme (2 ed.). Almanya: telc $\mathrm{GmbH}$.

Aytan, N. (2015). Yaratıcı okuma: Kuram ve uygulama. Ankara: Nobel.

Blake, R. J. (2008). Brave new digital classroom: Technology and foreign language learning Washington, D.C.: Georgetown University Press.

Carnine, D. W., Silbert, J., Kame'enui, J. E., Tarver, S. G., \& Jungjohann, K. (2006). Teaching struggling and atrisk readers: A direct instruction approach (3 ed.). Upper Saddle River, New Jersey: Pearson Merrill Prentice Hall.

Ceyhan, E. (2007). Yabancı dil ögretimi teknolojisi. İstanbul: Morpa Kültür Yayınları.

Chang, W.-Y. (2016). A study on the effects of blogs in efl process/genre-based writing classrooms and its relationship with college students' writing strategies. (Doktora Tezi), Durham Üniversitesi.

Çoklar, A. N. (2014). Web ortamında çoklu ortam tasarımı. In Ö. Ö. Dursun \& F. Odabaşı (Eds.), Çoklu ortam tasarımı (2 ed., pp. 217-234). Ankara: Pegem Akademi.

Day, R. R. (1993). New ways in teaching reading. Illinois: Pantagraph Printing.

Durkin, D. (1989). Teaching them to read. Boston: Allyn and Bacon.

Durmuş, M. (2013). Yabancılara Türkçe öğretimi. Ankara Grafiker Yayınları.

Fellner, T., \& Apple, M. (2006). Developing writing fluency and lexical complexity with blogs. The Jalt Call Journal, 2(1), 15-26.

Gunning, T. G. (2014). Assessing and correcting reading and writing difficulties (5 ed.). Boston: Pearson.

Hashemi, M., \& Najafi, V. (2011). Using blogs in english language writing classes. International Journal of Academic Research, 3(4).

Hokanson, K., \& Long, C. (2012). Blogs. In S. McLeod \& C. Lehmann (Eds.), What school leaders need to know about digital technologies and social media (pp. 3-11). San Francisco, CA: Jossey-Bass.

Huang, H.-Y. C. (2016). Students and the teacher's perceptions on incorporating the blog task and peer feedback into EFL writing classes through blogs. English Language Teaching, 9(11), 38.

İnceoğlu, M. (2011). Tutum algı iletişim (6 ed.). Ankara: Siyasal Kitabevi.

İşman, A. (2011). Öğretim teknolojileri ve materyal tasarımı (4 ed.). Ankara: Pegem Akademi.

Jennings, J. H., Caldwell, J. S., \& Lerner, J. W. (2006). Reading problems: Assessment and teaching strategies. Boston, USA: Pearson Education.

Kazanc1, R. (2012). The use of blogs and the internet to enhance the writing skills of EFL learners. (Yüksek Lisans Tezi), Akdeniz Üniversitesi, Antalya. 
Kennedy, K. (2003). Writing with web logs. Technology and Learning Magazine, 23.

Lin, M. H. (2012). Blog assisted language learning in the EFL writing classroom: An empirical study. (Doktora Tezi), University of Birmingham.

Lipson, M. Y., \& Wixson, K. K. (2013). Assessment and instruction of reading and writing difficulty: An interactive approach (5 ed.). New Jersey: Pearson.

Mayer, R. E. (2009). Multimedia learning (2 ed.). Cambridge: Cambridge University Press.

McDonough, J., \& Shaw, C. (1993). Materials and methods in ELT: A teacher's guide. Oxford: Blackwell.

MEB. (2007). Öğrencilerin okuma düzeyleri. Ankara: Millî Eğitim Bakanlığı, Eğitimi Araştırma ve Geliştirme Dairesi Başkanlığı (EARGED).

Noytim, U. (2010). Weblogs enhancing EFL students' English language learning. Procedia - Social and Behavioral Sciences, 2(2), 1127-1132.

Özdemir, E. (2015). The effect of the use of blogs on motivation in EFL writing. (Yüksek Lisans Tezi), Balıkesir Üniversitesi, Balıkesir.

Özden, Y. (2008). Öğrenme ve öğretme (7 ed.). Ankara: Pegem Akademi Yayıncılık.

Özmen, H. (2013). Öğretim araç gereçlerinin teorik temelleri. In N. Yiğit (Ed.), Öğretim teknolojileri ve materyal tasarımı (5 ed., pp. 68-91). Trabzon: Celepler Matbaacılık.

Rashtchi, M., \& Hajihassani, H. (2010). Blog-assisted Language Learning: A Possibility in Teaching Reading to Iranian EFL Learners. International Journal of Language Studies (IJLS), 4(4), 245-262.

Robinson, R., Molenda, M., \& Rezabek, L. (2008). Facilitating learning. In A. Januszewski \& M. Molenda (Eds.), Educational technology: A definition with commentary (pp. 15-48). New York: Lawrence Erlbaum Associates.

Sainsbury, M. (2004). Children's attitudes to reading. Education Review, 17(2), 49-54.

Silberstein, S. (1994). Techniques and resources in teaching reading. Oxford University Press: Oxford.

Sun, Y. C. (2010). Extensive writing in foreign-language classrooms: A blogging approach. Innovations in Education and Teaching International, 47(3), 327-339.

Türker, M. S. (2018). Yabancı dil olarak Türkçe öğretiminde blog kullanımının okuma becerisine etkisi. (Doktora Tezi), Hacettepe Üniversitesi, Ankara.

Vurdien, R. (2012). Enhancing writing skills through blogs in an EFL class. European Association for ComputerAssisted Language Learning (EUROCALL), 155-158.

Warschauer, M. (2011). Learning in the cloud: How (and why) to transform schools with digital media. New York: Teachers College Press.

$\mathrm{Wu}$, H.-J. (2015). The effects of blog-supported collaborative writing on writing performance, writing anxiety and perceptions of efl college students in Taiwan. (Doktora Tezi), University of South Florida. 